\title{
Artigos
}

\section{Governança e educação permanente em saúde: avaliação de mecanismos, contextos e resultados no Projeto Apoiadores*}

Governance and permanent health education: evaluation of mechanisms, contexts and results in the Supporters Project (abstract: p. 13)

Gobernanza y educación permanente en salud: evaluación de mecanismos, contextos y resultados en el Proyecto Apoiadores (resumen: p. 13)

Poliana Avila Silva ${ }^{(a)}$

<poliana_avila@hotmail.com>

Célia Maria Gomes Labegalini ${ }^{(b)}$

<celia-labegalini-@hotmail.com> (iD)

Magda Lúcia Félix de Oliveira(c)

<mlfoliveira@uem.br> (D)

Grace Jacqueline Aquiles ${ }^{(d)}$

<gjaquiles@uem.br>

Vanessa Denardi Antoniassi Baldissera(e)

<vanessadenardi@hotmail.com>

\author{
* Pesquisa financiada pela \\ Organização Pan-Americana \\ de Saúde e Secretaria \\ Executiva/Departamento de \\ Articulação Interfederativa \\ do Ministério da Saúde e \\ Conselho de Secretarias \\ Municipais de Saúde do \\ Paraná (COSEMS-PR). \\ (a) Pós-graduanda do Programa \\ de Pós-Graduação em \\ Enfermagem (Doutorado), \\ Centro Ciências da Saúde \\ (CCS), Universidade Estadual \\ de Maringá (UEM). Avenida \\ Colombo, 5790, Campus \\ Universitário, Bloco 2, sala 1. \\ Maringá, PR, Brasil: 87020-900.
}

O estudo objetivou avaliar os mecanismos, contextos e resultados do apoio institucional do estado do Paraná relacionados com a governança em saúde. Trata-se de pesquisa avaliativa, qualitativa, ancorada na avaliação realista. Foram realizados 15 grupos focais com 83 gestores municipais de saúde e seis apoiadores regionais. Os dados foram organizados em matriz avaliativa e analisados segundo os preceitos da governança em saúde e Educação Permanente em Saúde (EPS). Procurou-se suscitar governança a partir das diretrizes de trabalho do referido projeto. Contextos habilitantes e restritivos foram evidenciados, bem como seus resultados. A EPS e o apoio institucional aos Conselhos Regionais dos Secretários Municipais de Saúde foram importantes diretrizes que desencadearam a governança colaborativa em distintos espaços da gestão em saúde.

Palavras-chave: Gestão em Saúde. Governança. Educação continuada. 


\section{Introdução}

A governança é uma forma de estruturação organizativa, que requer o envolvimento de atores públicos e privados no processo de tomada de decisão coletiva e formal para garantir consenso orientado e deliberativo ${ }^{1}$.

Na gestão pública em saúde, orientada pelos princípios doutrinários e organizativos do Sistema Único de Saúde (SUS), a governança em saúde institui coparticipação e corresponsabilização dos entes públicos envolvidos na cogestão intergovernamental ${ }^{2}$ e tem demandado novas conformaçôes de parcerias e trabalhos coletivos pelos gestores da saúde.

Nessa direção, o apoio institucional foi uma iniciativa do Ministério da Saúde (MS) para fins de implementação, monitoramento e avaliação das políticas, programas e açôes de saúde sustentadas nos princípios de regionalização que requerem governança ${ }^{3}$.

Nesse contexto, o apoio institucional no Paraná, sob responsabilidade do Conselho de Secretarias Municipais de Saúde do Paraná (COSEMS-PR), foi intitulado Projeto Apoiadores do COSEMS-PR, criado em 2011 e ancorado na perspectiva de instrumentalização da gestão em saúde. O Projeto Apoiadores do COSEMS-PR foi concebido como estratégia para aglutinar esforços e instituir a gestão participativa, o fortalecimento da governança frente aos espaços decisórios, a descentralização e autonomia dos municípios nos cotidianos da gestão $\mathrm{o}^{4}$.

No Projeto Apoiadores do COSEMS-PR, as ações são desenvolvidas por meio do trabalho dos apoiadores que são profissionais de nível superior com expertise e/ou experiência prévia na gestão do SUS. Atuam como facilitadores dos processos de mudanças na gestão por meio do apoio direto aos gestores municipais de saúde, culminando na efetivação dos Conselhos Regionais dos Secretários Municipais de Saúde (CRESEMS) e no empoderamento de gestores municipais 4 .

Enquanto estratégia de qualificação da gestão em saúde, o Projeto Apoiadores do COSEMS-PR apresenta potencial em fomentar mudanças na atuação de gestores, tendo a governança em saúde como objeto de trabalho, mas careciam evidências científicas sobre o processo de apoio e seus influentes. Esse cenário tornou profícua a presente pesquisa de avaliação realista ${ }^{5}$ cujos elementos permitiriam reconhecer o que desse Projeto funciona, por que funciona e em quais circunstâncias funcionam 5 .

Para tanto, esta pesquisa pautou-se na seguinte questão: como o Projeto Apoiadores do COSEMS-PR estimula e fortalece a governança em saúde?

Nesse contexto, objetivou-se avaliar os mecanismos, contextos e resultados do apoio institucional do Estado do Paraná relacionados com a governança em saúde.

\section{Metodologia}

Tratou-se de uma pesquisa avaliativa, de abordagem qualitativa, ancorada no referencial de avaliação realista ${ }^{5}$ que se fundamenta no realismo crítico. Por isso, foi conduzida pelos conceitos-chave de mecanismo, contexto e resultados capazes de fazer compreender "o que deste programa viabiliza seu funcionamento" no que se refere à governança em saúde. 
O local do estudo foi o Estado do Paraná: este possui 22 regiões de saúde organizadas em quatro macrorregiôes, e estas atuam na representação administrativa intermediária da secretaria de saúde estadual, colaborando no apoio aos municípios.

A pesquisa teve como público-alvo apoiadores e gestores em saúde envolvidos no Projeto Apoiadores do COSEMS-PR. O critério de inclusão foi: desenvolver atividades no referido projeto por, no mínimo, três anos, por compreender como tempo razoável para que o apoiador e gestor tivessem agregado vivências que permitissem a avaliação proposta. Foram excluídos os participantes apoiadores que não tivessem disponibilidade de tempo para participar da coleta de dados ou que não respondessem ao convite após três tentativas.

A pesquisa contou com a parceria da equipe diretiva do COSEMS-PR para levantamento do público-alvo e contato com os participantes elegíveis. Dessa forma, foram eleitos 280 gestores e oito apoiadores, dos quais 83 gestores e seis apoiadores participaram seguindo os critérios de inclusão e exclusão.

Os dados foram coletados por meio da técnica de grupo focal (GF), que estimula o discurso, a participação e a interação social ${ }^{6,7}$ e é indicada para pesquisas avaliativas ${ }^{8}$.

Foi utilizado um roteiro de questóes, elaborado pelas pesquisadoras e adequados quanto à forma e ao conteúdo por um grupo de seis juízes, composto por sete dimensôes avaliativas que abordavam aspectos estruturais, desenvolvimento das ações, percepção do papel do apoiador e repercussões das ações do Projeto Apoiadores do COSEMS-PR, além de questôes sobre potencialidades, fragilidades e sugestôes em relação ao projeto.

Foram realizados $15 \mathrm{GFs}$, sendo dois com apoiadores e $13 \mathrm{com}$ gestores municipais de saúde, que contaram com a participação de três a 13 integrantes (média de oito participantes), além da presença de um moderador e um observador, com duração média de quatro horas cada encontro.

Os GFs ocorreram entre os meses de agosto e novembro de 2017 e foram realizados em quatro cidades da macrorregião Norte, duas cidades da macrorregião Leste, três cidades da macrorregião Oeste e quatro cidades da macrorregião Noroeste, assim escolhidas pela facilidade de deslocamento dos participantes do estudo.

As discussões suscitadas nos GFs foram gravadas em áudio e transcritas na íntegra em documento no Microsoft Office Word ${ }^{\circledR}$. Posteriormente, desses dados foram extraídas as informaçôes, que foram organizadas em uma matriz avaliativa ${ }^{9}$, segundo as diretrizes da (EPS) e Apoio Institucional dos CRESEMS propostas no Plano de Trabalho 2016/2017 do COSEMS/PR ${ }^{4}$, por guardarem os direcionamentos da governança em saúde.

Ainda, nessa matriz, foi organizado o mecanismo do Projeto Apoiadores do COSEMS-PR, que gerou efeitos de governança em saúde; os contextos em que as intervençôes de governança em saúde foram introduzidas; e resultados, enquanto consequências aspiradas 5 de governança em saúde.

Assim, a matriz avaliativa foi disposta nas seguintes dimensões: questão ordenadora; mecanismos; diretrizes do plano de trabalho do Projeto Apoiadores do COSEMS-PR 2016/2017; contextos habilitantes e restritivos; e resultados alcançados.

Vale salientar que o plano de trabalho do Projeto Apoiadores do COSEMS-PR 2016/2017 atende à legislação da responsabilidade do COSEMS-PR quanto ao 
planejamento bianual das açóes do projeto frente às necessidades e demandas dos gestores municipais de saúde paranaenses ${ }^{4}$.

A análise foi realizada à luz dos preceitos da governança em saúde 3 , assumida como estratégia para o fortalecimento de vínculos entre os entes envolvidos com foco na tomada de decisões e definição de responsabilidades inerentes à gestão colaborativa e estratégica em saúde. A governança em saúde foi, ainda, discutida com base na sua estreita relação com os preceitos da EPS enquanto atuação coletiva e ação educativa pelo e no trabalho ${ }^{10}$.

O presente estudo compôs uma pesquisa maior, intitulada "Avaliação: Cinco Anos do Projeto Apoiadores COSEMS/PR”, a qual possui parecer no 2.071.304/2018 (CAAE: 67804617.3.0000.0104), e seguiu todas as normas éticas da experimentação humana constantes na Resolução no 510/2016 do Conselho Nacional de Saúde e complementares ${ }^{11}$.

\section{Resultados}

Foi possível evidenciar que governança em saúde, enquanto mecanismo do Projeto Apoiadores do COSEMS-PR, foi fomentada em estreita relação com as diretrizes de EPS e Apoio institucional aos CRESEMS constantes no plano de trabalho vigente do COSEMS-PR, que definiram uma gama de açôes desenvolvidas no projeto.

Foram também desvelados os contextos habilitantes e restritivos para a governança em saúde do Projeto Apoiadores do COSEMS-PR anunciados pelos apoiadores e gestores, bem como seus resultados (figura 1).

Questão: Em quais circunstâncias as ações do Projeto Apoiadores do Conselho de Secretarias Municipais de Saúde do Paraná (COSEMS-PR) fomentaram a governança?

Diretriz 1: Educação Permanente em Saúde (EPS)

Mecanismo: Suscitar Governança

Diretriz 2: Apoio institucional aos Conselhos Regionais dos Secretários Municipais de Saúde (CRESEMS)

Contextos habilitantes na perspectiva de apoiadores: (Re) organização e concretização dos CRESEMS; formação de cãmaras técnicas.

Contextos habilitantes na perspectiva de gestores: Reuniões itinerantes do CRESEMS contemplando outras cidades além do município sede das Regionais de Saúde (RS); Comissão Intergestores Bipartite (CIB) direcionada às demandas reais das regiões; Valorização do gestor na Comissão Intergestores Regional (CIR); Atuação da consultoria temática

Contextos restritivos na perspectiva de apoiadores: Resistência de gestores quanto o entendimento da atuação dos CRESEMS; Dificuldade do gestor em expor para prestadores e regionais os resultados das discussões realizadas nas reuniões do CRESEMS; Limitações políticas dos gestores.

Contextos restritivos na perspectiva de gestores: Apoiadores interferem nas decisões de gestores; Dificuldade das RS de aceitarem o Projeto Apoiadores; Questões políticas da administração municipal; Dificuldade apresentada pela CIR em respeitar decisões do CRESEMS

Resultados: Apoio aos CRESEMS e Grupos Condutores (GC) contando com maior participação dos gestores; Existência de entraves para as mudanças de processo de trabalho dos gestores, como falta de autonomia em processos decisórios, verticalização de direcionamentos advindos da gestão municipal e articulações políticas; Fortalecimento dos municípios de menor porte; Gestor assumiu seu papel na gestão e se fortaleceu-se nas discussões nos espaços decisórios; Projeto deu voz aos gestores e visibilidade junto ao Estado, prestadores e consórcios.

Figura 1. Matriz Avaliativa: Governança em saúde promovida pelo Projeto Apoiadores do COSEMS-PR. 
O mecanismo da governança em saúde apreendido por este estudo permitiu destacar o papel horizontal da EPS para a governança em saúde. Nesse sentido, os contextos habilitantes foram apontados como aqueles envolvidos na (re)organização de instâncias gestoras regionais e proposição de reunióes itinerantes, bem como a formação e o fortalecimento de câmaras técnicas como espaços de construção de consensos.

Tais contextos contribuíram para o reconhecimento do gestor em espaços decisórios, assim como a consultoria temática, observados nas seguintes falas:

A situação atual de organização dos gestores favorece o apoiador a contribuir muito para a organização e para que o CRESEMS aconteça, para que os secretários se reúnam e discutam as coisas, não pensando na sua necessidade, mas pensando regionalmente. Eu acho que nós, enquanto apoiadores, auxiliarmos na organização, é fundamental. (Apoiador)

Enquanto apoiadora, nas regióes, nós temos os grupos técnicos, os grupos temáticos, as câmaras técnicas [...] E é fundamental o nosso apoio, porque nós norteamos muitas discussóes nesses espaços, que fortalecem os grupos. (Apoiador)

Após a realização do Projeto Apoiadores e a nossa inserção nos grupos de discussão, houve maior valorização do gestor na CIR [Comissão Intergestores Regional]. (Gestor)

No tocante aos contextos restritivos, foram descritos como limitaçóes, dificuldades de compreensão sobre a importância do CRESEMS, das políticas impostas aos gestores e na interferência de apoiadores nas tomadas de decisóes, ilustrados nos seguintes recortes das discussóes:

Tem muitas coisas que, às vezes, os gestores falam nas reunióes de CRESEMS, mas que, por medo de represália, não falam diretamente para a Regional ou para o prestador. $\mathrm{O}$ apoiador apresenta essas demandas e faz a mediação. (Apoiador)

Os próprios gestores não assumem seu papel de líder nos momentos de discussão e de tomada de decisão. (Apoiador)

Tem gestor que não tem uma formação específica da área da saúde, que precisa realmente para atuar no cargo [...], mas às vezes o apoiador vendo aquilo, sem querer queria ser gestor também, principalmente nas decisões. (Gestor)

Há uma dificuldade de o prefeito entender as necessidades dos gestores e respeitar a gestão em saúde. (Gestor) 
Como resultado, destaca-se que açóes do Projeto Apoiadores do COSEMS-PR ampliaram o protagonismo dos municípios, principalmente os de pequeno porte, e estimularam a participação dos gestores nos espaços formais de discussóes, negociaçóes e pactuaçóes. Desse modo, os gestores garantiram maior autonomia em relação ao Estado, prestadores de serviços e consórcios intermunicipais de saúde.

\section{Discussão}

O processo de governança em saúde sugere pactuação entre entes e fortalecimento de vínculos, em um processo implicado na corresponsabilização para a tomada de decisóes ${ }^{3}$. Dessa forma, está imbricada ao apoio institucional do CRESEMS que se dá por meio de ações cujas características guardam preceitos emancipatórios da práxis que materializam a EPS.

Articulado ao processo organizativo das instâncias gestoras do SUS, os conselhos representativos da gestão regional, nomeados CRESEMS, adotam princípio básico do fortalecimento da atuação gestora municipal, que possui a capacidade de aproximar os gestores - dada sua característica regionalizada - apoiada na instrumentalização das práticas para melhorias da saúde da população ${ }^{12}$. Esse aspecto transformador do fazer em saúde fomentado pelo diálogo problematizador da realidade coletiva é a característica marcante da EPS ${ }^{13}$.

A materialização da governança em saúde perpassa a capacidade que gestores possuem em organizar os CRESEMS enquanto espaços de discussão, entre outras açóes. Diante desse cenário, o Projeto Apoiadores do COSEMS-PR atua na perspectiva de articular, junto com os gestores, a concretização desses espaços e a compreensão da importância do protagonismo destes frente às demandas municipais e regionais.

Além disso, é preciso oportunizar o desenvolvimento da capacidade crítica e reflexiva de gestores frente aos processos decisórios desencadeados pela troca de saberes proporcionados nos encontros, balizado em torno do processo de trabalho, que é uma prática eminente de EPS $^{10}$.

Educação, saúde e trabalho são práticas sociais interrelacionadas e sensíveis às forças de dominação e libertação ${ }^{13,14}$. Discuti-los é ato formativo enquanto ambiente de trabalho vivo e em transformação. Nessa perspectiva, ambientes dialógicos que permitem a superação do fazer alienado - como os espaços do CRESEMS, Comissóes Intergestores Regionais (CIR) e Comissóes Intergestores Bipartite (CIB), que foram alteradas pelo Projeto Apoiadores do COSEMS-PR - culminam na construção e atualização de saberes ${ }^{15} \mathrm{com}$ implicações importantes no processo de trabalho e mudanças de práticas, corroborando as premissas da EPS.

Assim, a EPS oportuniza uma prática reflexiva e dialógica a partir dos processos desencadeados no trabalho, suscitando o protagonismo dos profissionais no processo ensino-aprendizagem ${ }^{16} \mathrm{e}$, nessa perspectiva, o Projeto Apoiadores do COSEMS-PR, enquanto ferramenta capaz de instrumentalizar a gestão municipal de saúde para o fortalecimento da governança em saúde, fomenta o empoderamento de gestores e assume seu uso ao adotar a EPS enquanto diretriz de trabalho. 
Cabe destacar que a adoção de abordagens dialógicas e problematizadoras pelo Projeto Apoiadores do COSEMS-PR são materializadas nas discussões das realidades vivenciadas nas demandas locais e na troca de experiências da atuação da gestão entre gestores, apoiadores e consultores temáticos. Esses momentos conduzem a instrumentalização e empoderamento dos atores envolvidos, efetivando a transformação de práticas, norteados pela EPS.

Espaços que estimulam a problematização, como os encontros do CRESEMS, permitem o levantamento e a identificação dos problemas e sua relação com determinados contextos e que são essenciais para adoção de novas formas de gestão, pois pautam-se na discussão de necessidades concretas e troca de saberes e de práticas $^{17}$.

No contexto habilitante para a governança, destaca-se a presença do gestor nos espaços decisórios de negociação e pactuação, o que reflete no fortalecimento da governança em saúde. Além disso, aponta a posse desse gestor no processo de gestão do SUS, além da desfragmentação da gestão do sistema na instituição desses espaços ${ }^{18}$ influenciada, segundo os gestores, pelo Projeto Apoiadores do COSEMS-PR.

Mesmo que ainda haja barreiras na apropriação de espaços destinados ao compartilhamento da gestão regional, como limitaçôes políticas e administrativas impostas pela gestão municipal aos gestores municipais de saúde (que interferem no poder de decisão destes) e dificuldades na compreensão por parte dos gestores da relevância de sua atuação nas instâncias de decisão e pactuações (evidenciada por este estudo), a presença dos gestores nas CIB e nas reuniôes de CRESEMS tem sido crescente e as açốes do Projeto Apoiadores do COSEMS-PR têm contribuído com este movimento.

As barreiras para a participação e valorização dos espaços dialógicos e decisórios também foram encontradas em outros estudos ${ }^{19,20}$.

Realizar reunióes do CRESEMS em locais distintos e de forma itinerante - ou seja, contemplando outras cidades além do município-sede das Regionais de Saúde (RS) - garantiu maior acesso dos gestores, principalmente de municípios de pequeno porte. Compreende-se que as ações dos gestores requerem articulação e parceria, pois quanto maior a participação destes em reunióes, encontros e eventos, maior seu contato com os pares.

Nessa perspectiva, a participação de municípios nos processos decisórios é capaz de fortalecer os espaços de cogestão, uma vez que a articulação de gestores frente aos desafios da gestão regional suscita compartilhamento de funções e responsabilidades ${ }^{21}$, com envolvimento de todos os municípios de maneira igualitária, horizontalizando a gestão.

A interdependência de recursos, açôes e capacidades mantém a autonomia do município e garante a governança em saúde ${ }^{22}$, essencial para a qualidade dos serviços ofertados e viabilizada pelos encontros nos espaços formais que são estimulados pelos apoiadores. 
Cabe destacar que espaços que articulam o protagonismo de gestores, construídos com os apoiadores, como no caso das câmaras técnicas, devem atuar como promotores de empoderamento e devem permitir aos envolvidos o desvelamento das relações de conflito e a construção de políticas públicas que fomentem a governança em saúde, por meio da ação-reflexão-ação dos atores ${ }^{21}$.

As câmaras técnicas são consideradas espaços importantes de atuação e qualificação das ações dos gestores, também presente na realidade das ações do Projeto Apoiadores do COSEMS-PR, uma vez que são capazes de promover direcionamentos de municípios na formulação de estratégias de gestão, na condução das políticas públicas de saúde, no planejamento e desenvolvimento das ações e na construção de consensos técnicos entre gestores e equipes. Assim, fortalecem a governança em saúde por meio da capacitação técnica e legal na garantia de maior eficiência e efetividade dos municípios no âmbito da saúde ${ }^{23}$.

Entretanto, contextos restritivos para a governança foram referidos e balizam-se em torno da incompreensão do papel do CRESEMS, cuja causa pode ser atribuída ao fato de o conselho possuir finalidade de instrumentalização, e não necessariamente de intervenção e controle. Assim, possui papel relevante na descentralização e na horizontalidade da gestão - preceitos ainda não incorporados na gestão em saúde ${ }^{12}$.

As forças políticas e a interferências de apoiadores também emergem como restritivos no processo de governança em saúde. Em relação à política, destacam-se dois elementos importantes que exercem influência na gestão em saúde: o MS, enquanto órgão político da saúde; e a política enquanto instituição partidária.

Nesse sentido, o MS e a sua forma de organização e atuação, por vezes, pode restringir a governança, pois ainda é organizado em uma lógica estruturada, pouco flexível e voltada para a subjetividades nacional ${ }^{20}$.

Por vezes, as mudanças de prioridades do próprio MS culminam em alterações nas políticas públicas de saúde, elaboradas sem coparticipação dos demais atores envolvidos na implantação e implementação de tais políticas e, nesse contexto de horizontalidade, também fragilizam as relações com os gestores, trazendo insegurança a estes ${ }^{20}$.

Além disso, as relações entre atores do Estado e do legislativo, com lógica partidária, podem ser realizadas em espaços de negociação que não os pactuados pelo SUS, nos quais existe pouco controle no que se refere à organização e definição de interesses ${ }^{20} \mathrm{e}$ que impactam diretamente na postura dos gestores.

Açốes verticalizadas e com temas/prioridades unilaterais e impostas, seja pelo governo ou pelos apoiadores, fragilizam o processo de governança local, segundo os participantes, e provocam tensóes na governança municipal e regional associadas às dificuldades $\mathrm{da}$ compreensão da complexidade da gestão do SUS, cada vez mais presente, bem como as relaçôes na dinâmica de aspectos políticos, institucionais e financeiros ${ }^{22,24}$.

Interferências político-administrativas na atuação da gestão em saúde, por vezes associadas inclusive aos apoiadores, podem causar descontentamento na atuação de gestores e dificultar a materialização das ações proposta no planejamento de trabalho da gestão municipal de saúde ${ }^{25}$. Essas interferências podem atuar como fatores impeditivos da ação autônoma e protagonista de gestores frente à concretização da governança em saúde. 
Como resultados, o Projeto Apoiadores do COSEMS-PR realizou discussões a respeito do processo de trabalho dos gestores municipais de saúde e sua organização, pautadas no cotidiano da gestão e no seu papel protagonista no processo de regionalização e governança em saúde. Dessa forma, o apoio pretendeu incorporar novos modos de gestão e capacidade de ampliação da análise e reflexão das barreiras e possibilidades de cogestão ${ }^{19,26}$, ficando evidente a adoção da EPS em todo processo de trabalho do Projeto Apoiadores do COSEMS-PR e sua relação com a governança em saúde.

Assim sendo, esse novo modelo de gestão estimulado pelo Projeto Apoiadores do COSEMS-PR não requer gestores capazes apenas de implantar políticas e novos modelos de atenção, mas que tenham também capacidade e competência para administrar graves problemas que se apresentam nesse processo.

É de fundamental importância que os gestores estejam preparados e cada vez mais qualificados para enfrentar os problemas e os desafios que se apresentam no processo de gestão em saúde ${ }^{27}$, destacando a necessidade de apoio institucional constante e de criação de dispositivos que os capacitem tecnicamente.

No que concerne à necessidade de fortalecimento da gestão do SUS em seu processo de regionalização e governança em saúde, o debate da autonomia da gestão em saúde deve ser capaz de transpor barreiras. Nesse sentido, sobre o movimento de mudança de práticas de gestores em saúde deflagrado mediante os desafios cada vez maiores impostos à gestão em saúde, justifica-se a adoção do apoio institucional como um dispositivo capaz de potencializar o protagonismo de gestores perante esse cenário.

\section{Considerações finais}

O estudo foi capaz de avaliar os mecanismos, contextos e resultados do Projeto Apoiadores que fomentaram a governança em saúde.

Cabe destacar a EPS como importante diretriz de trabalho do Projeto Apoiadores do COSEMS-PR, que foi capaz de contribuir de forma significativa com o reconhecimento do papel protagonista de gestores de saúde perante a gestão municipal e governança regional em saúde frente aos processos decisórios e espaços de negociação e pactuação.

Para além do reconhecimento de maior atuação dos gestores municipais de saúde, a EPS, enquanto diretriz de trabalho do Projeto Apoiadores do COSEMS-PR, instrumentalizou todos os atores envolvidos com as açôes do Projeto, inclusive apoiadores, e corroborou a reflexão das práticas frente à construção e fortalecimento da governança em saúde.

Dessa forma, a avaliação sistemática do Projeto Apoiadores do COSEMS-PR, com a adoção do referencial proposto para esta pesquisa, e a análise da governança em saúde subsidiada por açóes de EPS possibilitaram o conhecimento formalizado de todos os aspectos inerentes ao andamento do projeto desde sua criação, uma vez que diversos aspectos, até então conhecidos de maneira informal, foram constatados na pesquisa segundo a perspectiva de apoiadores e gestores. 
Portanto, cabe destacar que, apesar de obstáculos a serem superados para concretização do apoio institucional, o projeto avaliado tem cumprido sua função enquanto ferramenta de qualificação da gestão, empoderamento de gestores e protagonismo na governança em saúde, por mudanças de práticas e gestão participativa.

Como limitação do estudo, reside a participação de gestores municipais de saúde e apoiadores, excluídos outros atores importantes na interface da execução do Projeto Apoiadores do COSEMS-PR, como trabalhadores das regionais de saúde e a equipe diretiva do COSEMS-PR.

Dessa forma, fica evidente a necessidade de mais estudos de cunho avaliativo nessa e em outras iniciativas de apoio institucional.

\section{Filiação}

(b) Departamento de Enfermagem, Universidade Estadual do Paraná. Paranavaí, PR, Brasil.

(c,e) Programa de Pós-Graduação em Enfermagem, CCS, UEM. Maringá, PR, Brasil.

(d) Departamento de Enfermagem, CCS, UEM. Maringá, PR, Brasil.

\section{Contribuições das autoras}

Todas as autoras participaram ativamente de todas as etapas de elaboração do manuscrito.

\section{Agradecimentos}

À Organização Pan-Americana de Saúde, à Secretaria Executiva/Departamento de Articulação Interfederativa do Ministério da Saúde e ao Conselho de Secretarias Municipais de Saúde do Paraná (COSEMS-PR).

\section{Direitos autorais}

Este artigo está licenciado sob a Licença Internacional Creative Commons 4.0, tipo BY (https://creativecommons.org/licenses/by/4.0/deed.pt_BR)..

\section{(cc) BY}




\section{Referências}

1. Martins HF. Governança colaborativa na prática: desafios das parcerias com organizaçóes sociais no Brasil. Rev Gest Paises Ling Port. 2016; 15(1):17-30.

2. Bretas Junior N, Shimizu HE. Reflexôes teóricas sobre governança nas regióes de saúde. Cienc Saude Colet. 2017; 22(4):1085-95.

3. Pereira Junior N, Campos GWS. O apoio institucional no Sistema Único de Saúde (SUS): os dilemas da integração interfederativa e da cogestão. Interface (Botucatu). 2014; 18 Supl 1:895-908.

4. Conselho de Secretários Municipais de Saúde do Paraná. Plano de Trabalho 2016/2017 do COSEMS-PR. Curitiba: COSEMS; 2017.

5. Pawson R, Tilley N. Realistic evaluation. London: Sage; 1997.

6. Backes DS, Colomé JS, Erdmann RH, Lunardi VL. Grupo focal como técnica de coleta e análise de dados em pesquisas qualitativas. Mundo Saude. 2011; 35(4):438-42.

7. Dall'Agnol CM, Magalhães AMM, Mano GCM, Olschowsky A, Silva FP. A noção de tarefa nos grupos focais. Rev Gauch Enferm. 2012; 33(1):186-90.

8. Trad LAB. Grupos focais: conceitos, procedimentos e reflexóes baseadas em experiências com o uso da técnica em pesquisas de saúde. Physis. 2009; 19(3):777-96.

9. Magalhães R. Implementação de programas multiestratégicos: uma proposta de matriz avaliativa. Cienc Saude Colet. 2014; 19(7):2115-23.

10. Brasil. Ministério da Saúde. Portaria no 198, de 13 de Fevereiro de 2004. Institui a política nacional de educação permanente em saúde como estratégia do Sistema Único de Saúde para a formação e o desenvolvimento de trabalhadores para o setor e dá outras providências. Diário Oficial da União. 16 Fev. 2004.

11. Brasil. Ministério da Saúde. Resolução no 510, de 7 de Abril de 2016. Dispõe sobre as especificidades éticas das pesquisas nas ciências humanas e sociais e de outras que utilizam metodologias próprias dessas áreas. Diário Oficial da União. 24 Maio 2016.

12. Shimizu HE, Cruz MS, Bretas Junior N, Schierholt SR, Ramalho WM, Ramos $\mathrm{MC}$, et al. O protagonismo dos Conselhos de Secretários Municipais no processo de governança regional. Cienc Saude Colet. 2017; 22(4):1131-40.

13. Baldissera VDA, Bueno SMV. A educação permanente em saúde e a educação libertária de Paulo Freire. Editorial. Cienc Cuid Saude. 2014; 13(2):191-2.

14. Freire P. Pedagogia do oprimido. 60a ed. São Paulo: Paz \& Terra; 2016.

15. Merhy EE. Educação permanente em movimento - uma política de reconhecimento e cooperação, ativando os encontros do cotidiano no mundo do trabalho em saúde, questôes para os gestores, trabalhadores e quem mais quiser se ver nisso. Saude Redes. 2015; 1(1):7-14.

16. Mishima SM, Aiub AC, Rigato AFG, Fortuna CM, Ogata MN, Silva MV, et al. Perspectiva dos gestores de uma região do estado de São Paulo sobre educação permanente em saúde. Rev Esc Enferm USP. 2015; 49(4):665-73.

17. Toledo P, Cruz M, Pinho R. Educação permanente em saúde: concepções e proposiçóes no Projeto de Formação e Melhoria da Qualidade de Rede de Atenção à Saúde (QualiSUS-Rede). J Manag Prim Health Care. 2018; 9:e17.

18. Cunha PF, Magajewski F. Gestão participativa e valorização dos trabalhadores: avanços no âmbito do SUS. Saude Soc. 2012; 21 Supl 1:71-9. 
19. Mendes A, Louvison MCP, Ianni AMZ, Leite MG, Feuerwerker LCM, Tanaka OU, et al. O processo de construção da gestão regional da saúde no estado de São Paulo: subsídios para a análise. Saude Soc. 2015; 24(2):423-37.

20. Casanova AO, Giovanella L, Cruz MM, Ferreira MFDC. Atores, espaços e rede de políticas na governança em saúde em duas regióes de saúde da Amazônia Legal. Cienc Saude Colet. 2018; 23(10):3163-77.

21. Kleba ME, Zampirom K, Comerlatto D. Processo decisório e impacto na gestão de políticas públicas: desafios de um Conselho Municipal de Saúde. Saude Soc. 2015; 24(2):556-7.

22. Machado SS, Moreira LCH, Nascimento MAA, Casotti E. Apoio institucional na ótica de gestores, apoiadores e trabalhadores: uma aproximação da realidade a partir de diferentes lugares. Interface (Botucatu). 2018; 22(66):813-25.

23. Brasil. Conselho Nacional de Secretários de Saúde. CONASS Debate - Uma agenda de eficiência para o SUS [Internet]. Brasília: CONASS; 2020 [citado 27 Fev 2019]. Disponível em: https://www.conass.org.br/consensus/conass-debate-uma-agenda-deeficiencia-para-o-sus/

24. Fernandes JA, Figueiredo MD. Apoio institucional e cogestão: uma reflexão sobre o trabalho dos apoiadores do SUS Campinas. Physis. 2015; 25(1):287-306.

25. Galavote HS, Franco TB, Freitas PSS, Lima EFA, Garcia ACP, Andrade MAC, et al. A gestão do trabalho na estratégia saúde da família: (des) potencialidades no cotidiano do trabalho em saúde. Saude Soc. 2016; 25(4):988-1002.

26. Bellini M, Pio DAM, Chirelli MQ. O apoiador institucional da Atenção Básica: a experiência em um município do interior paulista. Saude Debate. 2016; 40(108):23-33.

27. Martins CC, Waclawovsky AJ. Problemas e desafios enfrentados pelos gestores públicos no processo de gestão em saúde. Rev Gest Sist Saude. 2015; 4(1):100-9. 
The study aimed to evaluate the mechanisms, contexts and results of the institutional support provided by the State of Paraná related to health governance. This is a qualitative evaluation research grounded on realist evaluation. A total of 15 focus groups were held with 83 municipal health managers and six regional supporters. The data were organized in an evaluation matrix and analyzed according to the precepts of health governance and Permanent Health Education. The adopted mechanism was to raise governance from the working guidelines of Projeto Apoiadores. Fostering and restrictive contexts were revealed, as well as their results. Permanent Health Education and the institutional support to the Regional Councils of the Municipal Health Departments were important guidelines that triggered collaborative governance in different spaces of health management.

Keywords: Health management. Governance. Permanent education.

El objetivo del estudio fue evaluar los mecanismos, contextos y resultados del apoyo institucional del Estado de Paraná relacionados con la gobernanza en salud. Este es un estudio evaluativo, cualitativo, anclado en la evaluación realista. Se realizaron 15 grupos focales con 83 gestores municipales de salud y seis apoyadores regionales. Los datos se organizaron en una matriz evaluativa y se analizaron según los preceptos de la gobernanza en salud y Educación Permanente en Salud. El mecanismo adoptado fue suscitar gobernanza a partir de las directrices de trabajo del referido proyecto. Se pusieron en evidencia contextos habilitadores y restrictivos, así como sus resultados. La educación permanente en salud y el apoyo institucional a los Consejos Regionales de los Secretarios Municipales de Salud fueron directrices importantes que desencadenaron la gobernanza colaborativa en distintos espacios de la gestión en salud.

Palabras clave: Gestión en salud. Gobernanza. Educación continuada. 